\title{
Mulheres de Negócios Comandam? Uma análise do discurso a partir do Editorial Sebrae sobre a mulher
}

\author{
Officer Business Women? An analysis of the SPeECH from the \\ Editorial SEbrae on WOMEN
}

Cristiane Gomes de SOUZA*

Resumo: O presente trabalho constitui uma análise preliminar aos estudos de construção da tese de doutoramento em Linguística, e tem por finalidade analisar, a partir dos fundamentos da Análise do Discurso de linha francesa com a filiação teórico-metodológica do Materialismo Histórico Dialético, a posição de sujeito assumida pelo presidente do Sebrae ao falar sobre e para a mulher de negócios em editorial publicado na Revista Conhecer Prêmio Sebrae Mulher de Negócios. O objetivo é observar, com a escritura do discurso do Capital e seus efeitos de sentidos, compreendidos nas contradições sociais, relações sócio-históricas e ideológicas que constituem o processo discursivo, como se constrói uma representação da mulher para a formação discursiva (FD) de mercado - que mobiliza dizeres e valores e, ao mesmo tempo, tenta mostrar-se como construindo um discurso novo sobre a mulher. A partir disso é possível analisar porque certas posturas são valorizadas e porque certos dizeres são materializados e outros silenciados pela publicação.

Palavras-chave: Análise do Discurso. Capital. Mulher.

Abstract: This study is a preliminary analysis of the doctoral thesis of building studies in Linguistics, and aims to analyze, from the fundamentals of French

* Doutoranda em Linguística pelo Programa de Pós-Graduação em Letras e Linguística, da Universidade Federal de Alagoas (PPGLL/UFAL). Mestra em Serviço Social (UFAL). Contato: cristianesouza_psi@hotmail.com 
Discourse Analysis with theoretical and methodological membership of Dialectical Materialism History, position the subject taken by the President of SEBRAE to talk about and the editorial businesswoman published in the Journal Knowing Sebrae Award businesswoman. The goal is to observe, with the writing of the Capital speech and its effects of meaning, understood in social contradictions, social historical and ideological relations that constitute the discursive process, how to build a woman's representation to the discursive formation (FD) market - mobilizing sayings and values, and at the same time tries to show how building a new discourse on women. From this it is possible to analyze why certain positions are valued and because certain sayings are materialized and others silenced publication.

Keywords: Discourse Analysis. Capital. Woman.

\section{Introdução}

O discurso foi, historicamente, se configurando como um campo teórico-metodológico que fornece subsídios para sua análise, destacando-se, pois, a Análise do Discurso (AD), que contribui com pesquisas em diversas áreas do conhecimento.

A reflexão promovida pela Análise do Discurso (AD), de origem francesa, surge na década de 1960 com Michel Pêcheux, e resulta da relação entre as contribuições do Marxismo, da Linguística e da Psicanálise e suas especificidades. E, sendo filiada teoricamente aos movimentos de estudos sobre o sujeito, a ideologia e a língua, a AD marca sua singularidade por tratar a relação da ideologia com a língua, trazendo para a reflexão o materialismo.

Nesse sentido, a Análise do Discurso (AD) considera o discurso como objeto de estudo, de acordo com Orlandi (2001, p. 15), "o discurso é palavra em movimento, prática de linguagem: com o discurso observa-se o homem falando". Essas considerações levam-nos a reforçar que o sujeito, ao produzir determinados sentidos, silencia outros, já que, constituído pela ideologia, acredita que controla os sentidos que faz circular e que ele não poderia significar de outra maneira. Nas relações discursivas, palavras, sentidos e sujeitos estão sempre em movimento, significando, em todo o tempo, de muitas e diversas maneiras, mas determinadas pela história. 
Como vemos, a Análise de Discurso passa a ser fundamental para o processo de sentidos tendo como ponto de partida o discurso. O objeto de nossa análise é o editorial da Revista Conhecer Prêmio Sebrae Mulher de Negócios', redigido por Luiz Barretto, presidente do Sebrae Nacional, e que tem como título: Mulheres Comandam os Novos Negócios no Brasil (2014). Em seu texto, o presidente trata da representação social da mulher que considera "de negócios" e, a partir de partes que privilegiamos como ponto de partida, trataremos de alguns aspectos, sobretudo para entender que as relações de trabalho no Capital ganham novos significados e complexidades a partir da inserção feminina no mundo dos negócios.

Consideramos, pois, que o editorial é um acontecimento discursivo, "é um ponto de encontro de uma atualidade e uma memória" (PÊCHEUX, 1990b, p. 17). Um acontecimento que produz sentidos. Sendo assim, para nortear as análises, consideramos a construção de três partes: a primeira apresenta os fundamentos teóricos relevantes sobre o Discurso e a AD que norteiam a análise da materialidade discursiva escolhida. A segunda versa sobre as questões de gênero, ao tratarmos os múltiplos papéis da mulher. A terceira parte comporta as análises do editorial pelo seu presidente, na condição de representante de uma ideologia.

\section{O Discurso e seu Funcionamento: um breve esboço de contexto}

A principal forma de comunicação da humanidade é a língua, e esta é desempenhada em forma de enunciados.

Segundo Bakhtin (2000), que inicia seu estudo sobre os gêneros de discurso ressaltando que todas as atividades humanas estão relacionadas à utilização da língua, e que, portanto, não é de admirar que tenhamos tanta diversidade nesse uso e uma consequente variedade de gêneros, essa atividade se concretiza "em forma de enunciados (orais e escritos) concretos e únicos, que emanam dos integrantes duma ou outra esfera da atividade humana" (p. 279).

${ }^{1}$ Edição especial de 2014, pelos 10 anos do Prêmio Sebrae Mulher de Negócios. O objetivo é apresentar as premiadas e seus relatos de vida como mulheres empreendedoras para incentivar o empreendedorismo feminino. 
Assim, por meio do estudo de enunciados proferidos nas várias esferas da atividade humana, podemos analisar as vivências, o modo de pensar e agir, a cultura, a ideologia e, também, os atos de comunicação que perpassam as sociedades. Nesse sentido, entendemos que, ao estudarmos um editorial, por exemplo, devemos relacioná-lo à realidade na qual é produzido. A história, a cultura, a ideologia, o social do homem está constantemente influenciando suas atitudes e seus discursos. Por isso, o discurso precisa ser analisado de acordo com suas condições de produção, ou seja, para que e para quem é destinado, e qual a visão de mundo dos interlocutores.

Com base no materialismo histórico, Bakhtin caracteriza todas as formas e meios de interação verbal entre os indivíduos como determinadas pela estrutura sociopolítica e que deriva das relações de produção. Além disso, o autor considera a palavra como ocupante de um papel de fenômeno ideológico por excelência, e afirma que

A palavra é o fenômeno ideológico por excelência. A realidade toda da palavra é absorvida por sua função de signo. A palavra não comporta nada que não esteja ligado a essa função, nada que não tenha sido gerado por ela. A palavra é o modo mais puro e sensível de relação social (BAKHTIN/VOLOCHÍNOV, 2006, p. 36).

Tanto é verdade que o autor ainda acrescenta:

A palavra penetra literalmente em todas as relações entre indivíduos, nas relações de colaboração, nas de base ideológica, nos encontros fortuitos da vida cotidiana, nas relações de caráter político, etc. As palavras são tecidas a partir de uma multidão de fios ideológicos e servem de trama a todas as relações sociais em todos os domínios. É, portanto, claro que a palavra será sempre o indicador mais sensível de todas as transformações sociais, mesmo daquelas que apenas despontam, que ainda não tomaram forma, que ainda não abriram caminho para sistemas ideológicos estruturados e bem formados (BAKHTIN/ VOLOCHÍNOV, 2006, p. 40). 
Segundo Bakhtin/Volochínov (2006), há muitas formas de linguagem e isso ocorre devido à diversidade da experiência social, ligada ao fluxo de produção verbal que imprimem à linguagem um caráter de produto não acabado, e em constante transformação, de acordo com o contexto em que é utilizada. Nesse debate, o autor, tendo o olhar voltado às teorias marxistas para elaborar suas proposições sobre linguagem, muito nos ensina ao dar especial atenção às questões acerca de infraestrutura e superestrutura. A primeira constitui-se das relações/meios de produção de uma sociedade, conjunto de forças econômicas materiais, fonte da superestrutura.

A infraestrutura é caracterizada como um amplo aparato social atuante de forma basilar e indispensável à vida humana em termos de sua constituição e sobrevivência. E, em consonância a essa base que se chama infraestrutura, tem-se a existência de uma superestrutura, alcançando o espaço das ideias, das opiniões, dos pensamentos, da construção de uma perspectiva ideológica que visualize de que forma se configura o funcionamento da infraestrutura e por qual representatividade, em termos de significação, ela projeta no sujeito que a constrói.

Para abordar essas questões, é fundamental resgatar o "Prefácio" da Contribuição à Crítica da Economia Política, em que Marx, de forma sintética, apontou sua conclusão quanto à forma como a organização social encontra-se estruturada:

A conclusão geral a que cheguei e que, uma vez adquirida, serviu de fio condutor dos meus estudos, pode formular-se resumidamente assim: na produção social da sua existência, os homens estabelecem relações determinadas, necessárias, independentes da sua vontade, relações de produção que correspondem a um determinado grau de desenvolvimento das forças produtivas materiais. O conjunto destas relações de produção constitui a estrutura econômica da sociedade, a base concreta sobre a qual se eleva uma superestrutura jurídica e política e à qual correspondem determinadas formas de consciência social. O modo de produção da vida material condiciona o desenvolvimento da vida social, política e intelectual em geral (MARX, 2006, p. 24). 
Observamos a ênfase que Marx confere, nesse texto, às relações entre o que ele designa por estrutura e superestrutura, ou entre o que ele chama de forças produtivas e relações de produção, ou entre formas de existência e de consciência. Considerando-se as relações, o texto indica a existência de uma totalidade composta pela estrutura econômica e superestrutura, com seu movimento, desenvolvimento e relações recíprocas.

A totalidade é, pois, colocada de modo concreto, com o ser humano enquanto sujeito histórico real, que no processo social de produção e reprodução cria a base e a superestrutura, forma a realidade social como totalidade de relações sociais. Indica, também, uma forma de dependência e claramente aponta onde ela reside: na estrutura econômica. Esta é a base sobre a qual se ergue todo o edifício da sociedade. Assim, cada modo de produção gera uma superestrutura que lhe é correspondente e que não é mais do que a expressão das relações materiais dialéticas.

Ao recuperarmos esses fundamentos teóricos, precisamos ratificar que a linguagem humana faz parte do complexo do trabalho e tem sua gênese nas necessidades surgidas por essa atividade vital para a manutenção da espécie humana. Para Lukács (1997, p. 34),

É sem dúvida possível deduzir geneticamente a linguagem e o pensamento conceitual a partir do trabalho, uma vez que a execução do processo do trabalho põe ao sujeito que trabalha exigências que só podem ser satisfeitas reestruturando ao mesmo tempo quanto à linguagem e ao pensamento conceitual as faculdades e possibilidades psicofísicas presentes até aquele momento, ao passo que a linguagem e o pensamento conceitual não podem ser entendidos nem em nível ontológico nem em si mesmos se não se pressupõe a existência de exigências nascidas do trabalho e nem muito menos com condições que fazem surgir o processo de trabalho.

No entanto, é imprescindível perceber que haverá sempre reciprocidade entre as necessidades do trabalho e a efetivação da linguagem, que se transformam simultaneamente. Sobre isso, Lukács (1997, p. 34) acrescenta: 
É obviamente indiscutível que, tendo a linguagem e o pensamento conceitual surgidos para as necessidades do trabalho, seu desenvolvimento se apresenta como uma ininterrupta e inalienável ação recíproca e o fato de que o trabalho continue a ser o momento predominante não só não suprime estas interações, mas, ao contrário, as reforça e as intensifica. Disto se segue necessariamente que no interior desse complexo o trabalho influi continuamente sobre a linguagem e o pensamento conceptual e vice-versa.

Assim, dos pressupostos teóricos tratados aqui em breve esboço, podemos salientar que, para o materialismo histórico-dialético, o entendimento da práxis discursiva requer a compreensão da linguagem em realidade objetiva com ênfase nas relações de produção tão amplamente abordadas por Pêcheux (1995), em Semântica e Discurso.

Daí que, a partir do que foi exposto, compreendemos como o discurso funciona e é produzido em um determinado momento histórico e social e como é tecido por "milhares de fios ideológicos" (BAKHTIN, 1990, p. 86). Pêcheux nos auxilia a análise ao afirmar que

o sentido de uma palavra, de uma expressão, de uma proposição, etc. [...], não existe 'em si mesmo' (isto é, em sua relação transparente com a literalidade do significante), mas, ao contrário, é determinado pelas posições ideológicas que estão em jogo no processo sócio histórico no qual as palavras, expressões e proposições são produzidas. [...] Poderíamos resumir essa tese dizendo: as palavras, expressões, proposições, etc., mudam de sentido segundo as posições sustentadas por aqueles que as empregam (PÊCHEUX, 1988, p. 160).

Dizendo de outro modo, resume Cavalcante (1999, p. 151) que

as condições de produção do discurso compreendem, fundamentalmente, os sujeitos falantes em constante relação com a cultura, a sociedade e a economia de um determinado momento histórico. Nessa inter-relação os sujeitos assumem posições em relação a determinadas formações ideológicas e discursivas. 
No processo de produção do discurso, como cita a autora, podemos reiterar que, no sentido atribuído por Bakhtin, ocorre um complexo processo de inter-relação entre "sujeitos falantes" e o meio social em que vivem e, nessa inter-relação, os sujeitos sustentam determinadas posições em relação a determinadas formações ideológicas. Estas são entendidas como um conjunto de valores, atitudes e representações historicamente definido em relação às classes em conflito: capital x trabalho, força capaz de intervir em outras forças em confronto, em uma dada formação social.

Segundo Pêcheux (1988, p. 160), as formações discursivas “determinam o que pode e deve ser dito (articulado sob a forma de uma arenga, um sermão, um panfleto, uma exposição, um programa, etc.) a partir de uma posição [ideológica] dada numa conjuntura". Nesse sentido, afirma que

é no interior das formações discursivas, pois, que os sujeitos podem manifestar as posições ideológicas que ocupam no meio social, mesmo que nessas posições esteja ocultada para o sujeito a fonte do seu dizer. Essa posição do sujeito é marcada por um efeito de 'onisciência' da subjetividade, produzida pela intervenção da ideologia de cunho idealista, que enaltece o sujeito como fonte do processo de produção e reprodução da vida e, portanto, enaltece as suas formas de representação: o sujeito tem a ilusão de que é dono do seu discurso (esquecimento 1) e que tem a autonomia na escolha das palavras que emprega no discurso que julga ser seu (esquecimento 2) (PÊCHEUX apud AMARAL, 2005, p. 33).

De fato, a formação discursiva determina "o que pode e deve ser dito" a partir do lugar, da posição social, histórica e ideológica de quem enuncia o discurso.

Ainda nesse contexto, vale enfatizar, que no movimento discursivo, há aproximações e distanciamentos entre uma formação discursiva e outras; é imprescindível dizer que os discursos não são idênticos entre si, mas resultados de um processo interdiscursivo. Em outros termos, Orlandi ressalta que o sujeito não é responsável pela enunciação: 
Pelo conceito de interdiscurso, Pêcheux nos indica que sempre já há discurso, ou seja, que o enunciável (o dizível) já está aí e é exterior ao sujeito enunciador. Ele se apresenta como séries de formulações que derivam de enunciações distintas e dispersas que formam em seu conjunto o domínio da memória. Esse domínio constitui a exterioridade discursiva para o sujeito do discurso (ORLANDI, 2002, p. 89).

Segundo a autora, nesse movimento discursivo de incorporar o já dito, mas representando-o como diferente, ela reafirma que operam dois processos: o Interdiscurso e o Intradiscurso. O primeiro incorpora elementos do préconstruído e regula a possibilidade dos sentidos do enunciado. O segundo permite que o sujeito intervenha no enunciado, no repetível; é o que possibilita ressignificar o já dito e se significar.

E foi nesse movimento dos discursos que surgiu Zandwais, pontuando as relações do sujeito com a forma-sujeito, sempre ressaltando a natureza lacunar desses processos, pois, como diz a autora,

as modalidades que relacionam os diferentes processos pelos quais passam as relações de identificação com o Sujeito Universal (as ideologias) não são evidentes, nem diretamente apreensíveis, enquanto formas de apropriação/ reprodução/transformação de efeitos préconstruídos que dominam os sentidos de seu dizer (ZANDWAIS, 2003, p. 4).

De fato, há importância em dizer que, nas relações discursivas, palavras, sentidos e sujeitos estão sempre em movimento. E, sendo o sujeito um ser capaz de interferir no processo sócio-histórico, no âmbito discursivo, isso acontece por meio de sua formação discursiva (FD) e formação ideológica (FI). Mais que isso, para que haja sentido, o homem é levado a interpretar, daí por que dizer que o gesto de interpretação é que efetiva a relação do sujeito com a língua, com a história e com os sentidos. Se não há um discurso em que a ideologia não esteja presente, não há sentido sem interpretação e este fato confirma a presença da ideologia.

Nas contribuições de Orlandi (2001), a ideologia é essencial para a construção do sujeito e dos sentidos. A língua é a materialidade específica do 
discurso, sendo esta materialidade específica da ideologia. Assim, não há discurso sem sujeito, nem tampouco sujeito sem ideologia e é desse modo que a língua faz sentido. "O indivíduo é interpelado em sujeito pela ideologia para que se produza o dizer” (ORLANDI, 2001, p. 46).

Assim sendo, o discurso se constitui como uma prática social determinada por uma formação ideológica e, ao mesmo tempo, lugar de elaboração e de difusão da ideologia (BAKHTIN, 2000). Dessa forma, sustentados no entendimento, de materialização da ideologia na linguagem/ discurso do sujeito/autor, que perpassa o sócio-histórico, pretendemos entender a abordagem do já mencionado editorial, proferido pelo presidente do Sebrae, Luiz Barretto, nos escritos sobre a mulher.

Destarte, importante entender ainda que, por seus direitos e deveres, o sujeito do capitalismo tem a impressão de ser um sujeito livre em suas escolhas. Nas palavras de Orlandi (2012, p. 16), "É o tempo do capitalismo, da imediatez, efeito ideológico que ao mesmo tempo constrói um sujeito livre e responsável e o significa pela irresponsabilidade". Em outros termos, um tempo "balançando ao sabor das circunstâncias. Funcionando no regime da impressão da liberdade”, como frisa Orlandi (2012, p. 18).

Assim se tem a ilusão de uma autonomia que é constituída ideologicamente como resultado de uma sociedade capitalista. E também considera o Estado interferindo nos processos de individualização do sujeito, como uma condição essencial para que se possa governar e garantir o interesse da classe dominante.

Para resumir, nessas condições, nosso entendimento sobre o discurso, recorremos a Pêcheux, que nos diz que:

Todo discurso é o índice potencial de uma agitação nas filiações sócio históricas de identificação, na medida em que ele constitui ao mesmo tempo um efeito dessas filiações e um trabalho (mais ou menos consciente, deliberado, construído ou não, mas, de todo modo, atravessado pelas determinações inconscientes) de deslocamento no seu espaço (PÊCHEUX, 1990b, p. 56).

Por conseguinte, considerando os fundamentos teóricos expostos, mesmo em breve esboço de contexto, para nos auxiliar a entender o 
funcionamento do discurso, entende-se que a Análise do Discurso e sua filiação no Materialismo Histórico Dialético é fundamental para compreender os antagonismos sobre os quais se sustentam o modo de produção capitalista dissimulados em duas formas ideológicas básicas - a do capital e do trabalho - a partir da função que exercem no processo de reprodução e transformação das relações de produção.

Em suma, por esses verdadeiros nexos será sempre possível analisar como uma materialidade discursiva produz sentidos e de que forma ele constitui significâncias para e pelo sujeito.

\section{Os Múltiplos Papéis da Mulher}

A inserção de mulheres profissionais nas mais diversas áreas do mercado de trabalho tem provocado mudanças que se estendem da esfera pessoal e profissional à própria sociedade. Embora não se trate de um fenômeno recente, o "empreendedorismo feminino"2 (SILVEIRA; GOUVÊA, 2008) desponta como mais que uma alternativa à complementação da renda familiar.

Além disso, o discurso sobre a mulher contemporânea é fruto das transformações ocorridas nas sociedades e dos discursos construídos sobre ela. As publicações voltadas ao público feminino fazem parte dessa transformação. As revistas destinadas a este público são um exemplo desse processo, pois representaram uma poderosa ferramenta na difusão não apenas de informação, mas também na construção e perpetuação de discursos dominantes, influenciando, de forma significativa, as práticas identitárias do público ao qual se destinam.

As mulheres sempre desempenharam um papel fundamental na vida das famílias: o cuidar. E quando ingressaram no mercado de trabalho, os cargos ocupados também estavam vinculados "ao cuidar": enfermeira, professora, doméstica. De acordo com Freitas (2007, p. 55),

Isso é explicado pelo fato de o 'cuidado' ser considerado um atributo tipicamente feminino, adquirido na esfera doméstica, ou seja, os saberes

\footnotetext{
2 Termo genérico que vem sendo utilizado para designar a iniciativa de mulheres que abrem um negócio próprio ou decidem trabalhar de forma autônoma.
} 
são aprendidos na socialização da mulher. Desse modo, as mulheres aparecem como mais propensas a certas profissões por serem consideradas 'naturalmente' qualificadas para elas.

Com os avanços nos direitos e conquistas das mulheres, temos outra realidade para a situação delas no mercado de trabalho: competitividade, salários incompatíveis com suas funções e qualificações, quando comparados aos salários dos homens, desenvolvimento de múltiplos papéis, dentre outros.

A sociedade, por ser histórica e dialética, muda de acordo com os meios de produção e a forma de organização. Desse modo, a sociedade se organiza e começa a definir múltiplos papéis aos seus indivíduos, e é a partir daí que surge o conceito de gênero na divisão social do trabalho, determinando o papel para os homens e o papel para as mulheres nesta organização social. Para Carloto (2001, p. 201-212),

O conceito de gênero diz respeito ao conjunto das representações sociais e culturais elaboradas a partir da diferença biológica dos sexos. Enquanto o sexo no conceito biológico diz respeito ao tributo anatômico, no conceito de gênero refere-se ao desenvolvimento das noções de masculino e feminino como construção social.

E quando falamos de gênero na divisão social do trabalho, vale dizer que, para o modelo patriarcal, à mulher cabe o desempenho de atividades afetivas, como o cuidado e educação dos filhos e de atividades domésticas não legalizadas ou remuneradas. Ao homem, cabe a execução de atividades instrumentais e intelectuais, vinculadas ao emprego legalizado/remunerado.

Contudo, em Marx ([s.d.], p. 451), evidenciamos que o início da utilização do trabalho das mulheres pelo capitalista foi facilitado pela introdução da maquinaria que, segundo ele, permitia o emprego de trabalhadores sem força muscular. À época, as mulheres eram consideradas parcialmente capazes do ponto de vista jurídico. O olhar sobre as mulheres é o olhar sobre seres indefesos e incapazes, dos quais o capitalista se aproveita para diminuir os salários dos homens adultos, roubar-lhes o trabalho e aumentar os lucros.

Dessa forma, ao se incluírem no mercado de trabalho, apesar de ser ainda de modo desigual ao homem, e continuar existindo preconceito e 
discriminação, as mulheres têm mais uma forma de direito adquirida. Conforme Freitas (2007, p. 20), “embora se verifique uma maior valorização de certas carreiras femininas, as mulheres ainda ocupam maior parte dos postos mais instáveis e de remuneração mais baixa, evidenciando a permanência das igualdades das relações sociais entre os sexos".

Sobre essas questões, não há dúvida de que, nas últimas décadas, a mulher está cada vez mais buscando novas formas de participação na sociedade, conquistando o seu espaço, se profissionalizando, estudando mais para disputar o concorrido mercado de trabalho. E isso ocorre tanto em países desenvolvidos como em países em desenvolvimento. Ainda assim, ao inserir-se no mercado de trabalho, a mulher adquire múltiplos papéis, visto que seu papel de esposa, mãe e dona de casa, inerentes à função social antes ocupada, continua sendo mantida, mas, agora, sua dedicação não é exclusiva ao lar. A mulher contemporânea, ao mesmo tempo em que é dona de casa, é também estudante e profissional, realizando, ainda, tarefas no meio social.

Além da realização profissional das mulheres, e que não acontece para a maioria, o trabalho está ligado também à própria subsistência e de sua família, pois, além de suas tarefas domésticas, no lar, suas atribuições também passam a ser de ordem financeira, visto que sua renda agora é incorporada à renda familiar. De acordo com Tavares (2010, p. 122),

no casamento moderno, a mulher, para ser respeitada, vê-se impelida a perseguir um crescimento do 'eu' e da realização profissional, mesmo que não tenha um projeto pessoal ou desejo de exercer atividades domésticas. O marido, por sua vez, incentiva a sua esposa a estudar ou trabalhar, desde que não interfira nos serviços domésticos, cuidados com a família e filhos, que permanecem uma responsabilidade feminina.

Ao contrário do homem, a mulher, ao se colocar no mundo do trabalho, relega a segundo plano a sua identidade profissional ao priorizar a família. Dessa forma, as mulheres, ao somar trabalho com atividades do lar, somam também, às consequências de seus múltiplos papéis, problemas relacionados até mesmo à sua própria saúde. Para Carloto (1998, p. 9), "As mulheres que somam serviço de casa com o trabalho assalariado não conseguem se recuperar da fadiga e do desgaste, e ficam mais sujeitas a dores, doenças e vários tipos de sofrimento físico e mental". 
Dessa forma, temos que o desdobramento dos novos papéis da mulher tem como consequência uma sobrecarga de funções, uma vez que ela é levada a assumir longas jornadas de trabalho por acumular tarefas dentro e fora de casa. Mais que isso, ao longo dos anos, a entrada da mulher no mundo do trabalho vem sendo acompanhada por grande discriminação, não só em relação à qualidade das ocupações, mas principalmente pela desigualdade salarial entre os sexos.

Conclui-se, portanto, que, apesar de suas lutas e conquistas, as mulheres ainda não alcançaram a tão sonhada e estimulada igualdade. Essa realidade amplia as possibilidades de investigação dos fenômenos influenciados por questões de gênero, já que o papel ocupado pela mulher (re)afirma o espaço inicial definido para sua atuação, restrita à esfera da vida familiar, como esposa e mãe.

\section{A Mulher no Discurso Sebrae e seus Efeitos de Sentido}

Por todo o exposto, sobre os múltiplos papéis femininos, procuramos iniciar os primeiros gestos de análises sobre o perfil da mulher atual segundo o discurso SEBRAE, quando selecionamos o editorial Revista Conhecer Prêmio Sebrae Mulher de Negócios, n. 25, do mês de fevereiro de 2014. A revista é uma publicação de reconhecimento sobre os 10 anos do Prêmio Sebrae Mulher de Negócios (PSMN), que valoriza o empreendedorismo feminino e traz assuntos que interessam à mulher, mas não que sejam específicos para ela.

Ao definir o material empírico, nas primeiras análises para essa pesquisa, apoiamo-nos na análise do corpus concentrada na composição de sequências discursivas extraídas do editorial da Revista Conhecer Prêmio Sebrae Mulher de Negócios pelo presidente do Sebrae Nacional, Luiz Barretto, em fevereiro de 2014, e seus efeitos de sentido.

O presidente, oriundo do Sebrae, torna-se o organizador dessa coletividade. Assume a posição discursiva de porta-voz que, na acepção pecheuxtiana, é o sujeito simultaneamente ator e testemunha do acontecimento. Por ser ator, participa das ações do grupo representado, mas se diferencia deste por ser o mediador das negociações com o adversário. Logo, é alvo privilegiado do olhar alheio. Por ser testemunha, tem visibilidade do acontecimento assim como o grupo; contudo, diferencia-se deste por visualizar 
melhor a participação de todos. Há, então, uma contradição constitutiva da figura do porta-voz: ora "igual" aos representados, ora "diferente" (PÊCHEUX, 1990a; ZOPPI-FONTANA, 1997).

A foto de capa, conforme vemos a seguir, traz imagens de mulheres de sucesso e, na abertura da revista, um editorial pelo presidente do Sebrae Nacional, Luiz Barretto, além de matérias pertinentes ao tema, que é colocado como sendo de interesse nacional e procura atingir, além dos leitores tradicionais, novos leitores, especialmente as mulheres que pretendem se inserir no mundo dos negócios e concorrer ao PSMN.

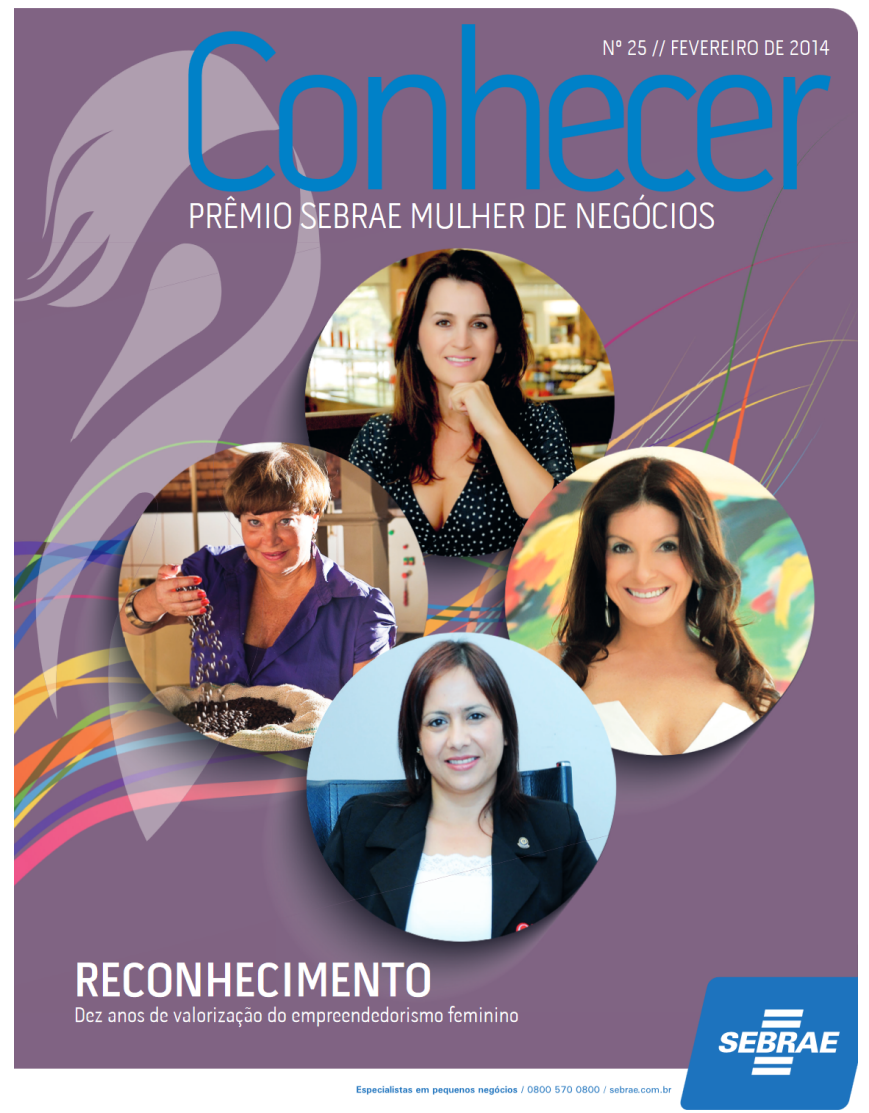

Fonte: Disponível em <http://bit.ly/2BzWZSd $>$.

Figura 1 - Capa da Revista Conhecer, n. 25 (fev. 2014). 
MULHERES

COMANDAM OS

NOVOS NEGÓCIOS

NO BRASIL

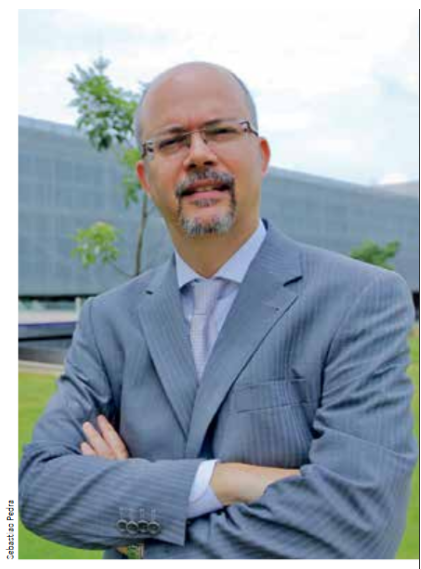

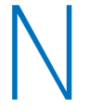

a última década, o Brasil avançou na construção de um modelo de desenvolvimento econômico acompanhado pela reduçào de disparidades sociais históricas. 0 empreendedorismo tem sido estratégico para estimular um processo simultâneo de inclusão e de ascensão social. E nesse contexto, as mulheres se destacam e ganham, cada vez mais, espaço no mercado.

0 mercado interno, que já soma 100 milhões de consumidores, fortalecido pela nova classe média, é um grande motivador para a geração de empresas comandadas por mulheres, principalmente no setor de Comércio e Serviços. Para clas, em especial, outra razão é muito atraente na troca de um emprego pelo negócio próprio: a flexibilidade de horários.

Segundo a pesquisa Global Entrepreneurship Monitor (GEM) 2013, rea- lizada no Brasil com apoio do Sebrae, o empreendedorismo brasileiro está mais feminino. A pesquisa mede, a cada ano, a cvolução do cmprecndedorismo $\mathrm{cm}$ mais de 60 países. Pela primeira vez, as mulheres são maioria entre os novos empreendedores: representam 52\% dos donos de pequenos negócios com até três anos e meio de atividade.

E o mais importante: $66 \%$ delas $\mathrm{cm}$ preendem por uma questão de oportunidade e não por necessidade. Ou seja, grande parte delas veem o empreendedorismo como uma opção de emprego que vai além da carreira tradicional em uma empresa pública ou privada. Mesmo assim, continuam cuidando das suas tarcfas familiares e dos seus projetos pessoais.

Atento a essas mudanças culturais e sociais, o Sebrae trabalha ainda mais para apoiar e fomentar o empreendedorismo feminino, com ações específicas de capacitação, consultoria e de reconhecimento de boas práticas. Uma delas ć o Prêmio Sebrac Mulher de Negócios, que completa 10 anos em 2014, e será a temática desta edição especial da Revisto Conhecer.

Há uma década mostramos histórias de sucesso de mulheres que acreditaram no sonho de ter seu próprio negócio. Elas tornaram-se exemplo de inspiraçào para potenciais empresárias que também alimentam o mesmo desejo. Considero promissor que os pequenos negácios estejam na dianteira de mudanças tão positivas. Somadas, são mais de $8 \mathrm{mi}$ lhôes de micro e pequenas empresas, o que equivale a $99 \%$ dos CNPJ do Brasil. E nesse universo, reconhecemos o mérito das mulheres, que se firmam no mercado com muito talento e qualificação. C

*Presidente do Sebrae Nacional

Fonte: Disponível em < http://bit.ly/2BzWZSd $>$.

Figura 2 - Edital da Revista Conhecer, n. 25 (fev. 2014). 
Acreditamos, pois, que os sentidos produzidos pelo discurso põem em relação ao dizer com sua exterioridade suas condições de produção, que compreendem fundamentalmente os sujeitos e a situação. Nesse caso, a memória discursiva faz parte também das condições de produção do discurso (ORLANDI, 2002).

Além disso, temos, como categoria, as formações ideológicas e as formações discursivas. As primeiras são matrizes comuns a um conjunto de discursos que expressam posições assumidas pelos sujeitos em diferentes práticas sociais. Em outras palavras, cada formação ideológica contém, necessariamente, como um de seus componentes, uma ou várias formações discursivas (CAVALCANTE, 1999). E a formação discursiva como sendo um conjunto de enunciados relacionados a um mesmo sistema de regras, historicamente determinadas.

E, para além de recorrermos às categorias supracitadas, há a necessidade de chamar a atenção sobre o gênero publicitário que pretendemos analisar, uma vez que se trata de um tipo de enunciado que tem como objetivo persuadir o leitor (as mulheres, especialmente) para a adesão à formalização de negócios e à inscrição ao prêmio. Na concepção de Bakhtin (2000), o processo de produção de um determinado gênero discursivo está intimamente ligado à sua função.

Assim sendo, faz-se importante dizer que o editorial, lugar de onde fala o presidente Luiz Barretto, é um lugar privilegiado, através dele se pode criar uma imagem para determinado fato ou alguém. Portanto, como já dito, ele se torna o organizador dessa coletividade, assumindo a posição discursiva de porta-voz, gerando uma contradição constitutiva da figura do porta-voz: ora "igual”, ora “diferente" (PÊCHEUX, 1990a; ZOPPI-FONTANA, 1997).

O presidente tece comentários sobre a mulher e, a partir deles, fizemos recortes para a nossa análise. Podemos perceber a recorrência ao passado e, nesse caso, o sujeito dialoga com sua memória discursiva na produção de sua formação discursiva.

Para a Análise do Discurso, nada na linguagem é indiferente ao sentido, é interessante destacar no texto, inicialmente, a palavra "COMANDAM", que indica relações de poder, demarcando hierarquias no meio social. Embora outras partes do texto generalizem um ideal de empreendedorismo feminino, só algumas mulheres podem ter acesso e representam, nesse sentido, referenciais de uma determinada classe da sociedade. 
A capa da revista traz, por exemplo, em si, uma memória, considerando o padrão de beleza de mulheres de sucesso ou perfil de mulheres de negócios já premiadas. E em se tratando da mulher que empreende, os efeitos de sentidos de "empreendedorismo" são considerados como atração às leitoras, referindo-se a uma "beleza" considerada ideal para ser buscada, ainda que nem sempre seja possível para todas as mulheres atingi-la.

Dessa forma, podemos considerar que a ideologia está presente nas formações discursivas que afetam a relação do sujeito com o mundo, com o outro e consigo mesmo. E os sentidos das palavras e imagens derivam de um conjunto de formações discursivas com uma dominante. O lugar social do falante e do ouvinte também carrega vários sentidos, o que nos levou a entender porque seria o enunciador Luiz Barretto, que além de apresentar alguns dados, incentiva mulheres a fazerem parte dos "novos negócios". E podemos analisar que escolher a mulher para falar sobre empreendedorismo não é, portanto, algo aleatório: essa escolha coincide com os interesses da Instituição, no caso o Sebrae, por sua atuação no mercado como forma de garantir a legitimidade do discurso.

Não apenas as palavras significam, Orlandi (2002, p. 42) enfatiza que "os sentidos não estão nas palavras elas mesmas. Estão aquém e além delas". As palavras, pois, significam de modo diferente de acordo com as posições daqueles que as empregam, isto é, elas mudam de sentido conforme as formações ideológicas nas quais essas posições se inscrevem.

Ademais, é importante destacar a força que a imagem, como função social, também tem na constituição do dizer. Por exemplo, a imagem que se pode ter de um "presidente" não surge do nada: ela se constitui entre o simbólico e o político, em processos que conectam discursos e instituições. E como a sociedade se constitui por relações hierarquizadas, são as relações de força, sustentadas no poder de diferentes lugares que significam na comunicação. O lugar do qual o sujeito fala é constitutivo do que diz. Assim, quando o sujeito fala a partir do lugar de presidente, suas palav ras produzem efeitos de sentido diferentes do que se ele falasse de outro lugar.

Desse modo, os serviços do Sebrae são apresentados, na voz de "presidente", como um passaporte para o mundo dos negócios, onde a mulher "comanda". Vejamos a Sequência Discursiva (SD) a seguir: 
SD1 - "Na última década, o Brasil avançou na construção de um modelo de desenvolvimento econômico acompanhado pela redução de disparidades sociais históricas. $O$ empreendedorismo tem sido estratégico para estimular um processo simultâneo de inclusão e de ascensão social. E nesse contexto, as mulheres se destacam e ganham, cada vez mais, espaço no mercado" (grifo nosso).

Ao falar das mulheres que "se destacam e ganham [...] espaço no mercado", o sujeito afirma, nessas condições de produção, a inserção da mulher no mundo do trabalho, inclusive por meio da ocupação em atividades que eram exercidas praticamente com exclusividade pelos homens.

Do que podemos analisar, essa inserção não é feita sem conflitos. $\mathrm{O}$ mundo do trabalho, até então predominantemente masculino, parece conceder confiança, sendo possível dizer que se estabelece uma escala crescente nesse lugar "no mercado" de mulheres no comando. E, apesar do discurso "redução de disparidades" ou igualdade de oportunidades para as mulheres, há evidências de que existem desigualdades na participação masculina e feminina no mercado de trabalho, seja em relação aos níveis salariais, possibilidade de crescimento na carreira ou de exercer determinadas funções. O que se nota é uma segregação velada e disfarçada que atinge as mulheres em relação ao trabalho e à ascensão das mulheres a níveis hierárquicos mais altos.

Nessas mesmas condições, as expressões "modelo de desenvolvimento econômico", "empreendedorismo", "inclusão", "ascensão social” são comumente encontradas nos discursos do Capital e que, na verdade, sugerem a existência de algo que transforma, um movimento de mudanças necessárias ao próprio mundo capitalista.

E em se tratando de movimento de mudanças ou de reorganização, entendemos que, de fato, a própria burguesia não pode existir sem revolucionar continuamente os instrumentos de produção, as relações de produção e todas as relações sociais. E seus discursos acabam orientando os indivíduos a anteciparem o seu futuro.

Nas palavras de Amaral (2005, p. 19), 
A mudança é o grande tema da ideologia do mercado na sociedade contemporânea: mudança da ordem mundial, mudança das relações de trabalho, mudança das formas de gerenciamento do processo de trabalho, mudança de paradigmas, mudança de comportamento, mudança 'dos processos de pensamentos de todos os empregados'. A mudança é o tema de discursos tecidos por milhares de fios ideológicos que orientam os indivíduos a viver o presente, engano o passado e antecipando o futuro.

$\mathrm{Na}$ SD1, o discurso do presidente do SEBRAE define que o empreendedorismo é o agente do "processo simultâneo de inclusão e de ascensão social". E o sentido de mudança, nesse caso, opera na dimensão da subjetividade, parafraseando o que Marx nos diz sobre as mudanças supracitadas.

E quando o sujeito do dizer, o presidente Luiz Barretto, trata da "redução de disparidades sociais históricas", possibilita um novo sentido, dado aos processos discursivos, de como as relações de trabalho na sociedade capitalista se pautam nos princípios de uma ideologia representada por uma formação discursiva do mercado, pois os elementos dessa formação se apropriam de discursos que falam de igualdade e de liberdade. Para tanto, o mercado seria a possibilidade para que os homens construam uma sociedade "livre", todavia tão somente justificada pela necessidade de "competirem" no mercado.

Nas próximas sequências discursivas, temos:

SD2 - "Pela primeira vez, as mulheres são maioria entre os novos empreendedores: representam 52\% dos donos de pequenos negócios com até três anos e meio de atividade. $\mathbf{E}$ o mais importante: $66 \%$ delas empreendem por uma questão de oportunidade e não por necessidade" (grifo nosso).

SD3 - “Ou seja, grande parte delas veem o empreendedorismo como uma opção de emprego que vai além da carreira tradicional em uma empresa pública ou privada. Mesmo assim, continuam cuidando das suas tarefas familiares e dos seus projetos pessoais" (grifo nosso). 
Das informações de Luiz Barretto, notamos, sim, uma significativa incorporação do trabalho feminino no mundo produtivo. Contudo, com a expansão do trabalho feminino, o que temos, além das desigualdades salariais, visto que sua remuneração é bem menor que a do trabalho masculino, é uma grande desigualdade na divisão do trabalho. A posição desigual de homens e mulheres no ambiente de trabalho determina diferentes consequências para ambos. A concorrência da atividade empreendedora com a dedicação à família, para a mulher, emerge conjuntamente com o início do empreendimento.

Ao contrário do homem, a mulher, ao se colocar no mundo do trabalho, soma seu trabalho com atividades do lar, e somam também, às consequências de seus múltiplos papéis, problemas relacionados até mesmo à sua própria saúde, como o desdobramento dos novos papéis da mulher, levada a assumir longas jornadas de trabalho por acumular tarefas dentro e fora de casa.

Barretto diz que " $66 \%$ delas empreendem por uma questão de oportunidade e não por necessidade”, e isso revela a

força do assujeitamento ideológico, e estar no simbólico é estar na estrutura da linguagem, ou seja, uma estrutura com sua ordem própria, enquanto um sistema de significantes regido por oposições e diferenças (MAGALHÃES; MARIANI, 2010, p. 396).

Mais que isso, notamos que os efeitos de sentido construídos nas sequências discursivas apontam para a possibilidade de superar a crise com coragem que caracteriza atitude individual, como o momento de oportunidade para a mulher empreendedora, segundo as palavras do presidente do Sebrae.

Analisamos, por meio da FD-Sebrae, que, para a mulher, agora, não tem mais barreiras. Ou seja, a crise é um cenário que pode ser favorável, se ela tiver "a ideia" para investir e a coragem para lutar. Dito de outro modo, a crise é contornada ou a sua gravidade é minimizada pela valorização da individualidade subjetiva. E será a partir da iniciativa individual que qualquer mulher pode alcançar o sucesso financeiro e profissional.

Contudo, quando Barretto diz que "grande parte delas veem o empreendedorismo como uma opção de emprego que vai além da carreira tradicional", observa-se que, apesar da vontade de empreender, as mulheres estão constantemente expostas a um conflito, uma vez que, mesmo 
empreendendo, continuam em função da família, não se desvinculam da família para se dedicarem tão somente aos seus negócios.

$\mathrm{E}$, de fato, isto pode ser explicado pela dupla jornada de tarefas de que a mulher fica incumbida quando gerencia seus negócios, bem como por ela se cobrar porque, como é dito pelo presidente do Sebrae, "Mesmo assim, continuam cuidando das suas tarefas familiares e dos seus projetos pessoais". Ou seja, para Barretto, a mulher não é retirada do âmbito doméstico, pois ele reforça o peso da dupla jornada de trabalho. Em suma, mulher que é de negócios deve saber lidar com as duas situações.

Para a mulher, o que podemos analisar é que a gestão dos negócios demanda maior dedicação de tempo e isso tem consequências na relação familiar. Assim sendo, a visão da mulher a partir dos anos 1990 é uma mulher que cuida da família, mas também trabalha e em muitos casos chefia a casa. Dessa forma, por todas as transformações sociais ocorridas, o discurso de que a mulher, além de empreender, deve cuidar do lar, do esposo e dos filhos ainda está enraizado na sociedade capitalista.

Nesse contexto, a mulher se apresenta para essa mesma sociedade capitalista como potencialidade de compra e de consumo e que, como consumidora, vai determinando também como os dizeres são organizados, ditos ou, por vezes, silenciados. O que notamos é que a ressalva sobre a mulher de negócios - uma mulher independente financeiramente e bemsucedida - confirma a permanência das contradições nos discursos sobre a mulher.

Sobre a sequência discursiva a seguir, podemos evidenciar as representações sociais por meio do "apoio" do Sebrae às mulheres empreendedoras, oferecendo "ações específicas de capacitação, consultoria e de reconhecimento de boas práticas”, com o objetivo de fortalecer a mão de obra do capital e propagar cada vez mais o sistema capitalista através da exploração do trabalho e do trabalho feminino.

SD4 "Atento a essas mudanças culturais e sociais, o Sebrae trabalha ainda mais para apoiar e fomentar o empreendedorismo feminino, com ações específicas de capacitação, consultoria e de reconhecimento de boas práticas. Uma delas é o Prêmio Sebrae Mulher de Negócios, que completa 10 anos em 2014. Há uma década 
mostramos histórias de sucesso de mulheres que acreditaram no sonho de ter seu próprio negócio. Elas tornaram-se exemplo de inspiração para potenciais empresárias que também alimentam o mesmo desejo" (grifo nosso).

Ao falar no editorial sobre "Mulheres Comandam os Novos Negócios no Brasil', e ao representar a formação discursiva do mercado, o presidente do Sebrae cria uma expectativa, fazendo com que a leitora confira o texto. De fato, o editorial cumpre essa intenção ao tratar sobre o Prêmio Sebrae Mulher de Negócios (PSMN). Porém, não é somente esse aspecto que foi trazido como objeto de análise.

Em outros termos, não se trata de o Sebrae somente "apoiar" as mulheres de negócios, mas queremos chamar a atenção para algo que é recorrente nas SDs: as mulheres se reconhecerão como "vencedoras" ou como "perdedoras", a partir da relação que estabelecem com o sistema de referência estabelecido pelo mercado por meio do PSMN - um prêmio que tem como finalidade levar as mulheres que possuem seu próprio negócio a se inscreverem no concurso (SEBRAE, 2008) que, todos os anos, premia mulheres que criam negócios de sucesso, premia as melhores experiências e, assim, gera exemplo, através de livros e vídeos contendo os relatos, para levar as demais leitoras a um processo de identificação.

E, ao mostrar as "histórias de sucesso de mulheres que acreditaram no sonho de ter seu próprio negócio”, o Sebrae revela um pensamento discursivo que expressa uma relação de poder entre sujeitos empíricos (mulheres) que se posicionam de forma diferente no mundo dos negócios. E ao dizer que as mulheres premiadas "tornaram-se exemplo de inspiração para potenciais empresárias que também alimentam o mesmo desejo”, Barretto convoca as leitoras a aprender com as vencedoras, influencia os pensamentos das mulheres para pensar no fato de que seus problemas já foram vividos e solucionados por outras mulheres de negócios que viveram as experiências por meio das mudanças. E, desse modo, o processo de identificação dos sujeitos, imitandoos ou comparando-se, é sustentado pela ideologia do mercado. E por que não dizer: seria esse processo uma forma de interpelação da ideologia na constituição da forma-sujeito? 


\section{Conclusão}

Os sentidos produzidos sobre o sujeito mulher, por meio das análises das sequências discursivas recortadas do editorial da Revista Conbecer, que serviram de corpus nesse artigo, permitiram entender como o discurso do presidente Luiz Barretto sobre a mulher constitui-se no discurso Sebrae.

Uma análise sobre o papel da mulher de negócios é de suma importância no entendimento da construção do discurso do mercado e, como vimos, analisar o discurso implica relacionar linguagem, história e sociedade.

Podemos dizer que, após verificação e análise dos escritos no editorial sobre a mulher, a partir das análises das sequências discursivas realizadas, pôde-se observar que, no interior da FD-Sebrae, existe a tentativa de mostrar à leitora que ela pode se inserir no mercado de trabalho, atuando profissionalmente e tendo independência financeira. E isso é o que determina, em última instância, como os dizeres são organizados, ditos e, por vezes, silenciados pelo discurso Sebrae.

Assim sendo, uma vez que diz considerar a posição feminina no mercado de trabalho, o Sebrae passa, num segundo movimento, a valorizar mais outras questões. O editorial continua abordando a temática do trabalho, mas o foco da discussão não está mais em se a mulher empreende ou se há problemática da equidade de gêneros na carreira. Como mostram as SDs analisadas, a valorização do indivíduo como ser capaz de vencer as adversidades pela força de vontade e por seu esforço particular e ser vencedor e reconhecido por Prêmio também parecem atender à lógica do modo de produção capitalista (e, por consequência, da FD-Sebrae).

Para tanto, é preciso que o sujeito acredite na possibilidade de ascender socialmente, de vencer as adversidades e de ter uma posição privilegiada, como faz o prêmio obtido pela conquista e pelo sucesso. Trata-se de uma esperança necessária para a manutenção do status quo, que deposita no sujeito a responsabilidade pelo seu sucesso (ou pelo seu fracasso). Lembrando que essa conquista só será alcançada pelo modo de produção capitalista, mesmo utilizando termos como "inclusão social", que apenas tem uma parcialidade do objetivo social, mas o que predomina é a sobrevivência do capital.

Além de entender que essa mulher, apresentando-a como livre, mas, ao mesmo tempo, submetendo seus desejos e sua vontade ao discurso 
capitalista, é possível notar que, ao estimular o empreendedorismo feminino, o discurso do presidente do Sebrae envolve as mulheres num discurso ideológico de uma escolha e de um querer legitimado, de maneira naturalizada.

Há relações de força nesse discurso que demonstra determinado grupo de mulheres diretamente envolvidas na produção de sentidos sobre o empreendedorismo, numa escala hierárquica, evidenciando relações de poder. E a publicidade, por meio da revista e do editorial, dá visibilidade aos sentidos que interessam a esses responsáveis pelo dizer, e que se tornam referência para os demais, especialmente para as mulheres.

Das análises aqui presentes, vale reiterar o quanto a $\mathrm{AD}$ contribui para entender o processo de produção de sentidos, considerando que a linguagem dá corpo aos sentidos (no que é dito), mas também implica sentidos silenciados, compreendendo ainda os "não ditos" no editorial da revista, mas que também dão movimento aos sentidos.

Vale salientar, por fim, que sobre essas análises elencadas neste texto, longe de esgotar o tema, ainda há muito a se dizer. A forma como delimitamos o nosso corpus determinou apenas os primeiros gestos de análise, mas o nosso objeto de estudo permanece aberto para novas leituras e análises, porque acreditamos que analisar os discursos sobre as mulheres de negócios não é suficiente para apagar velhos discursos sobre a mulher.

\section{Referências}

AMARAL, M. V. B. Discurso e relações de trabalho. Maceió: EDUFAL, 2005.

BAKHTIN, M. Questões de literatura e de estética: a teoria do romance. 2. ed. Tradução Aurora Fornoni Bernadini et al. São Paulo: Hucitec, 1990.

BAKHTIN, M. Os gêneros do discurso. In: BAKHTIN, M. Estética da criação verbal. 3. ed. São Paulo: Martins Fontes, 2000.

BAKHTIN, M./VOLOCHÍNOV. A relação entre a infra-estrutura e as superestruturas. In: Marxismo e filosofia da linguagem. 9. ed. São Paulo: Hucitec, 2006. 
CARLOTO, C. M. A saúde das trabalhadoras. In: BARRETO, M.; CARLOTO, C. M.; COSTA, M. L. DA. Saúde das trabalhadoras. São Paulo: SOF, 1998.

CARLOTO, C. M. O conceito de gênero e sua importância para a análise das relações sociais. Serviço Social em Revista, Londrina, v. 3, n. 2, p. 201-213, 2001.

CAVALCANTE, M. do S. A. de O. Implícitos e silenciamentos como pistas ideológicas. Leitura, Análise do Discurso. n. 23, 1999.

FREITAS, T. V. O cenário atual da divisão sexual do trabalho. São Paulo: SOF, 2007.

LUKÁCS, G. O trabalho. Tradução Ivo Tonet. Maceió: 1997. (Mimeo).

MAGALHÃES, B.; MARIANI, B. Processos de subjetivação e identificação: ideologia e inconsciente. Linguagem em (Dis)curso, Palhoça, v. 10, n. 2, p. 391-408, maio/ago. 2010

MARX, K. O Capital: crítica da economia política. Livro I, v. I. 24. ed. Trad. Reginaldo Sant'Anna. Rio de Janeiro: Civilização Brasileira, 2006.

MARX, K. O Capital. Livro 1, v. 1. Rio de Janeiro: Civilização Brasileira, [s.d.].

ORLANDI, E. P. Análise de discurso: princípios e procedimentos. Campinas: Pontes, 2001.

ORLANDI, E. P. As formas do silêncio no movimento dos sentidos. Campinas: Unicamp, 2002.

ORLANDI, E. P. Sentidos em fuga: efeitos da polissemia e do silêncio. In: CARROZZA, G. et al. (Org.). Sujeito, sociedade, sentidos. Campinas: RG, 2012.

PÊCHEUX, M. Semântica e discurso. Uma crítica à afirmação do óbvio.

Tradução Eni Pulcinelli Orlandi et al. Campinas: Editora da Unicamp, 1988.

PÊCHEUX, M. Lecture et mémoire: projet de recherche. In: MALDIDIER, D. L'inquiétude du discours: textes de Michel Pêcheux.

Chapitre IX. Éditions des Cendres, 1990a. p. 285-293. 
PÊCHEUX, M. O discurso: estrutura ou acontecimento. Campinas: Pontes, 1990b.

PÊCHEUX, M. Semântica e discurso. Campinas: Unicamp, 1995.

SEBRAE. Conhecer Prêmio Sebrae Mulher de Negócios, n. 25, fev. 2014.

Disponível em: <http://bit.ly/2BzWZSd>. Acesso em: 15 maio 2015.

SEBRAE. Disponível em: <http://bit.do/dVAMv>. Acesso em: 15 de outubro de 2008.

SILVEIRA, A.; GOUVÊA, A. B. T. de. Empreendedorismo feminino: mulheres gerentes de empresas. FACES - R. Adm. Belo Horizonte, v. 7, p. 124-138, jul./set. 2008.

TAVARES, M. S. Com açúcar e sem afeto: a trajetória de vida amorosa de mulheres das classes populares em Aracaju/SE. Serviço Social \& Sociedade, São Paulo, n. 101, p. 121-145, mar. 2010. Disponível em: <http://bit.ly/2z18S0Y>. Acesso em: 13 maio 2014.

ZANDWAIS, A. A forma-sujeito do discurso e suas modalidades de subjetivação: um contraponto entre saberes e práticas. In: SEMINÁRIO DE ANÁLISE DE DISCURSO: Michel Pêcheux, uma relação de nunca acabar, 1., 2003, Porto Alegre. Anais... Porto Alegre: UFRGS, 2003. Disponível em: $<$ http://bit.ly/2B6RMR3 $>$.

ZOPPI-FONTANA, M. Cidadãos modernos: discurso e representação política. Campinas: Editora da Unicamp, 1997.

Recebido em: 09/07/2016

Aceito em: 10/11/2016 